\title{
Panthera pardus fusca (Family: Felidae) Diet Composition from Lamjung, Nepal
}

\author{
Sagar Raj Kandel \\ Central Department of Environmental Science, Tribhuvan University, Nepal
}

Copyright $\mathrm{C} 2019$ by authors, all rights reserved. Authors agree that this article remains permanently open access under the terms of the Creative Commons Attribution License 4.0 International License

\begin{abstract}
With the increasing threats to leopard associated mainly with human activities and decline in prey species, leopard population is at risk and is known to use areas outside the protected areas. Community forest might be the important source for the long-term population sustainability of leopard. This study was conducted in Thuli community forest of Lamjung, Nepal. In this study, non-invasive sampling techniques for the collection of scats adopted. Total $(n=40)$ scats were collected opportunistically. The presence of leopard was confirmed by indirect signs of pugmarks, scats, scratches and kill of cattle in the shed. A total of 12 prey species were successfully identified based on the medullary and cuticle structure of hair samples. Around $55.20 \%$ of leopard diet was contributed by domestic animals followed by wild animals, which signifies the conflict with the study area. Rodents and bird's species had also contributed in the diet of leopard with $10.98 \%$ and $7.54 \%$ respectively. Around $8.17 \%$, portion of diet contribution was from primates. Devoid of wild prey and abundance of domestic animals in scats contents highlight the urgent need of conservation intervention in the area and strengthening the community tolerance.
\end{abstract}

Keywords Community Forest, Leopard, Domestic Animals, Wild Prey, Lamjung, Scats Content, Diet Composition

\section{Introduction}

For the habitat tolerance and its ability to feed on wide range of animals, Leopard Panthera pardus (Family; Felidae) has the widest range of distribution among the large felids (8). Despite their wide range of distribution from dunes of sand to the mountain, they are threatened by the factors like habitat loss and degradation, reduction of prey due to hunt for bush meat, illegal wildlife trade and persecution of leopard by local communities in revenge of livestock loss and human injuries. Globally, leopard is regarded as vulnerable in International Union for Conservation of Nature (IUCN). Conservation of International Trade in Endangered Species of Wild Fauna and Flora (CITES) listed leopard in Appendix-I.

In Nepal, their distribution is up to $41,000 \mathrm{~m}$ above the mean sea levels (5). Being one of the top predators, presence of leopard has a potential role in ecosystem. However, the importance of conservation of leopard in Nepal is somewhat neglected as compared to tiger. At the same time, few researches on the diet and population status of leopard in Terai region are taking place mainly focusing on the protected areas $(12,13)$. Large carnivores adapt themselves in human-dominated landscape (3), with complete dependence of nutrition supplemented by domestic animals as prey (4). This versatility in diet allows leopards to survive in rural area with human population (3, 4, 10).

The initiation of community forest in Nepal in 1993 has not only helped in protecting forests. Community forest's potential to sustain the leopard population cannot be denied. Presence of natural prey base needs to be considered. Mainly the researches on the diet of leopard from mid hills are absent. The study provides the diet composition of leopard from Thuli Community forest and adjoining forest area. With an aim to answer the certain questions: 1) What are the prey species taken by leopards? And do leopards prey on domestic animals? I have adopted the scat analysis techniques. For me, documentation of leopard was the most essential, before I collected the scat samples.

Study on diet composition helps in the conservation of leopard in community forest, because the community forest in future might be regarded as the potential habitat to harbor the population of leopard in Nepal. And their presence is related to conflicts, which district forest offices have no institutional capacity to respond as compared to attempts to resolve the problems concentrated around the protected areas. 




Figure 1. Study area, Thuli Community forest and adjoining area 


\section{Study Area and Methods}

The study was conducted in Thuli community forest and adjacent forest area with an area $12.58 \mathrm{~km}^{2}$. It is located between $28^{\circ} 11^{\prime} 12^{\prime \prime} \mathrm{N}$ to $28^{\circ} 11^{\prime} 53^{\prime \prime} \mathrm{N}$ and $84^{\circ} 25^{\prime} 30^{\prime \prime} \mathrm{E}$ to $84^{\circ} 26^{\prime} 34^{\prime \prime}$ E. Vegetation found are mainly chilaune (Schima wallichii), Katus (Castanopsis hystrix), Sal (Shorea robusta). The study area lies within the elevation of $600 \mathrm{~m}$ to $1000 \mathrm{~m}$. Mid- Marsyangdi Hydro Project lies at the southern part of the study area.

\subsection{Collection of Scats}

The non-invasive sampling techniques were adapted for the collection of samples. All total 40 scats samples were collected. I had searched the scats of leopard since October, 2018 to April, 2019. During the search of scats, I had walked along the forest trails where the signs of leopards were found to occur. Local people were also asked about their presence in the study area in order to collect the scats samples for easiness and avoid the time constraints. The scats samples were collected in zip-lock plastic bags and labelled with GPS location and date.

\subsection{Analysis of Scats}

Scat analysis was done in the lab of Central Department of Environmental Science. The majority of samples collected were old. The samples were dipped in Lysol solution in order to prevent hair breaking during the successive draws of 20 hairs sample from each scat (7). Each hair was dipped in 10\% Sodium Hypochlorite and Ethanol solution for 30 minutes separately. The hairs samples were dried in blotting paper. Temporary slides were prepared to observe the cortex and medulla region of hair with the help of Olympus microscope under the magnification of $40 \mathrm{X}$ and 100X. For the observation of medulla region, each sample was treated in xylene for 24 hours. The microphotographs obtained from the present research (domestic animals only) were tallied with the specimens prepared during this study, while wild prey references from the former study was used.

\subsection{Relative Biomass Calculation}

As the frequency of occurrence does not give the exact estimation, smaller prey species could be overestimated and number of scats of prey species could be misleading. For the calculation of relative biomass, equation developed by Ackerman from the study of cougar food habits in southern Utah (2) was adopted, which is assumed to have the same digestive system with leopard.

$$
\mathrm{Y}=1.980+0.035 \mathrm{X}
$$

Where, $\mathrm{Y}=$ Weight of prey consumed per scat $\mathrm{X}=$ live body weight $(\mathrm{kg})$

\subsection{Confirm Documentation of Leopard}

For the confirmation of leopard from the study area, I had searched for pugmarks and scrapes. In order to maximize the presence of leopard during the period of research, I had made a frequent visit to Thuli community forest and local people. During my first field visit, I had successfully documented the fresh kill of cattle within the community. And pugmarks were also confirmed. This is not the first case of livestock depredation by leopard; several cases were underscored.

\section{Results}

\subsection{Diet Analysis}

From the diet analysis, 12 prey species were detected. The wild preys present in the scats were jungle cat (Felis chaus) and Barking deer (Muntiacus muntjak) with frequency of occurrence $3.64 \%$ and $18.18 \%$ respectively. Most of the prey species were domestic livestocks with $29.1 \%$ which includes house pig, buffalo, cattle and goat (Table 1). All total $67.5 \%$ of scats contain one prey species, whereas $32.5 \%$ of scats contained two prey items. The scat of leopard frequency of occurrence of rodents and birds were around $16 \%$ and $10 \%$ respectively. Such high frequency for both species might be due to the difficulty in species level identification. Two prey items were primates namely Macaque (Macaca mulatta) and Langur (Semnopithecus entellus) (Table 1).

\subsection{Relative Biomass Consumed}

A significant amount of diet was contributed by domestic livestock, around $46 \%$ (Table 2). Among the potential domestic prey, the relative biomass contribution by cattle was $26.61 \%$, followed by goat $10.67 \%$, buffalo $4.45 \%$ and house pig $4.03 \%$ (Table 2). Barking deer alone contributes $16.48 \%$ of diet to leopard (Table 2). Rodent species and bird species had also contributed in the diet of leopard with $10.98 \%$ and $7.54 \%$ respectively (Table 2 ). Some amount of diet contribution was from primates, around $8.17 \%$ (Table 2). 
Table 1. Frequency of occurrence of different prey species in leopard scats

\begin{tabular}{|c|c|c|}
\hline Species & No. of scats with prey species & Frequency of occurrence (\%) (A) \\
\hline Jungle cat & 2 & 3.64 \\
\hline Barking deer & 1 & 18.18 \\
\hline Buffalo & 1 & 1.82 \\
\hline House pig & 2 & 3.64 \\
\hline Cattle & 7 & 12.73 \\
\hline Macaque & 4 & 7.27 \\
\hline Langur & 2 & 3.64 \\
\hline Cat & 2 & 3.64 \\
\hline Dog & 4 & 7.27 \\
\hline Goat & 6 & 10.91 \\
\hline Rodent & 9 & 16.36 \\
\hline Bird & 6 & 10.91 \\
\hline
\end{tabular}

Table 2. Composition of leopard scats, to calculate relative biomass consumed

\begin{tabular}{|c|c|c|c|}
\hline Species & Body weight $(\mathrm{kg})(\mathrm{B})$ & Correction factor $(\mathrm{kg}$ of prey per scat) $(\mathrm{C})$ & Relative biomass consumed (\%) (D) \\
\hline Jungle cat & 3.5 & 2.10 & 2.59 \\
\hline Barking deer & 20 & 2.68 & 46.48 \\
\hline Buffalo & 150 & 7.23 & 4.03 \\
\hline Pig & 37 & 3.28 & 26.61 \\
\hline Cattle & 120 & 6.18 & 5.39 \\
\hline Macaque & 6 & 2.19 & 2.78 \\
\hline Langur & 8 & 2.26 & 2.59 \\
\hline Cat & 3 & 2.10 & 5.90 \\
\hline Dog & 12 & 2.40 & 10.67 \\
\hline Goat & 26 & 2.89 & 10.98 \\
\hline Rodents & 0.1 & 1.98 & 7.54 \\
\hline Birds & 1.8 & 2.04 & \\
\hline
\end{tabular}

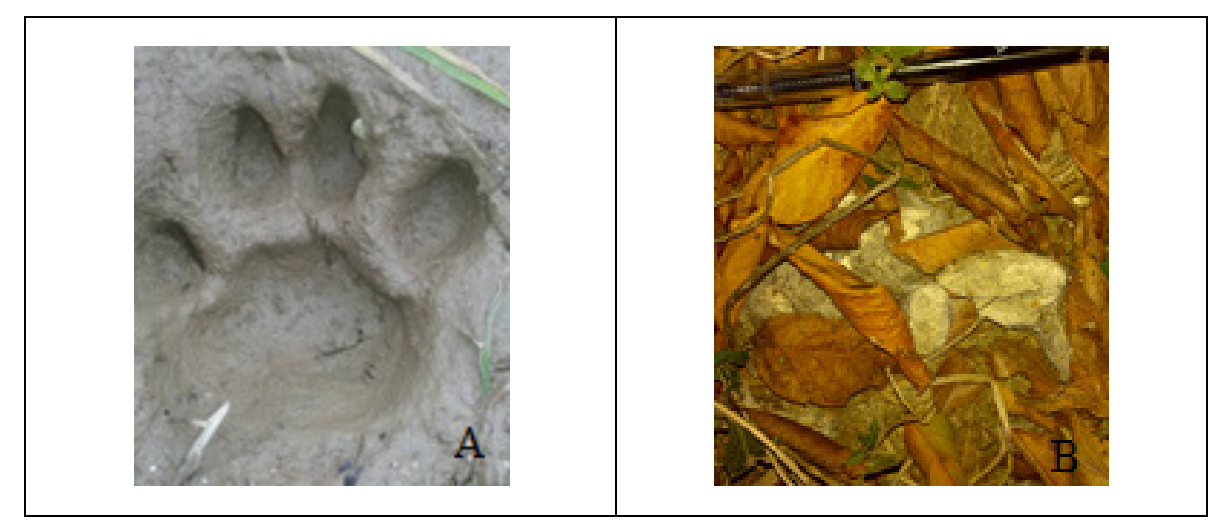




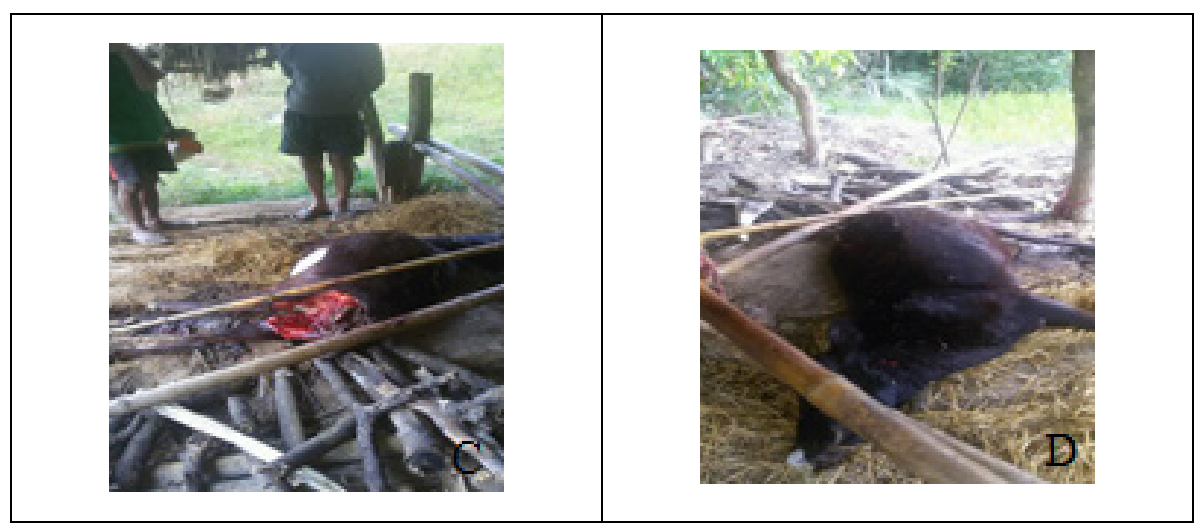

Figure 2. A) Pugmark of leopard in rice field B) Scats of leopard in Thuli community forest C) Cattle killed in shed D) Scratch made on the cattle

\subsection{Confirm Documentation of Leopard}

For the confirm detection of leopard indirect signs like pugmark, scats and scrape were searched in the forest. Fine pugmark of leopard was detected in the rice field that confirms the presence of leopard in the study area. However, local people were also asked about the presence or absence of leopard and informed me about the domestic livestock. Cattle were killed in the shed during my first visit in the field. After the observation of dead cattle in the shed and public review and pugmark search around the field the predator was confirmed to be a leopard.

\section{Discussions}

Non-invasive sampling technique has been adopted for the estimation of diet of leopard from the Thuli community forest and adjoining area from, Lamjung, Nepal. A range of studies have estimated the biomass contribution by wild preys and domestic animals in leopard diet. However, most of the researches on leopard's diet focused on Terai (12), with no absence from Himalayan regions. Several of the research conducted in Terai and Himalayan region also signifies the leopard diet has been mostly contributed by domestic livestock.

A total of 40 scats reveal that the presence of 12 prey species from the present study, which is less than the study conducted in Southern Africa from a conservation area and rangelands which analyses 18 prey species from same total number of scats (9).

Thuli community forest has no other apex predators present except leopard, which was confirmed through the indirect signs of pugmarks, scats, scratches and with kill of cattle in the sheds. This study was conducted in human-dominated landscape where people are found to involve themselves in pastoralism. In this case, domestic animals are found, and leopard diet primarily subsists on domestic animals $(3,4)$. Around $87 \%$ of leopard diet in the human-dominated landscape from Ahmednagar district, Maharastha, India, was supported by domestic animals where only few species of wild animals were reported (4).
Diet of leopard also include small carnivore namely jungle cat, which contributes the relative biomass of $2.59 \%$ in leopard diet. With no surprise, small carnivore viz. leopard cat (Prionailurus bengalensis) had contributed biomass at around $0.7 \%$ in diet of Indochinese leopard (11). Barking deer was one of the major prey species of leopard from Thuli community forest and adjacent area, besides the cattle. As they move towards the dense forest and form the group as antipredator strategy (1). Meanwhile, the people living alongside the forest have cattle, goat, buffalo which lack the antipredator ability. Additionally, the variety of indigenous prey might be less in number that could fulfill the nutritional requirement of leopard which tempted the leopard to kill livestock. This fact sometimes might not be true according to the study on changes in wolf diet in Italy in relation to increase in ungulates density (6).

Furthermore, a shortcoming of scat analysis in scats contents may be associated with a scavenging event rather than predation event, which has not been fulfilled by this study. However, this data provides a first description of the diet of leopard from Thuli community forest and adjacent area. Indirect sighting of leopard during the field had confirmed the presence of leopard in the study area. During the night and even inside the shed, livestock had been successfully killed (Figure 2C), which signifies the pressure of human-leopard conflict and their lower ability to cope with this situation.

It is evident that rodents and birds have also contributed around $10 \%$ and $7 \%$ of relative biomass in leopard diet (Table 2). This signifies the importance of rodents and bird's contribution in leopard diet where wild animals are lacking and predation on domestic animals sometimes bring risk to leopard, as pastoralist persecute leopards, and are connected with livestock kills. The lack of indigenous prey species in the forest area might have compelled leopard to fulfill their nutritional requirement by rodents and birds, and it is also the reason for domestic animals' being killed. On the other hand, leopard might have shown the dietary shift towards rodents and birds (11) for this the reason is still unknown. It is worth contribution to leopard diet which had been fulfilled by dog and cat from the study area. The reason behind the ingestion of dog and cat may 
be associated with its ignorance by owners. Dog is not kept at kennel till the evening and is found roaming in the area, and it is the same for the cat. Otherwise, dogs and cats ingested might be feral.

The utilization of primates namely macaque and langur in this study does not differ from other study too.

\section{Conclusions and Recommendation}

Study adds the value of community forest from hilly region where the leopards are found to occur. Although this study is the preliminary study to detect the leopard presence in community forest, compositing the diet of this elusive species has always been challenging. This study was conducted in regard to the conservation of leopard, and motivate the researchers and planners to think on the status of leopard in multiuse land especially where the preys are scarce and their potential threat of persecution is related to livestock depredation and human injuries and casualties are always associated with them.

From the research, leopard diet is supplemented by domestic animals, which signifies the tendency to stir up the human-leopard conflict. Although the incidents of domestic livestock had taken place in the human-dominated landscape around Thuli community forest and adjoining area, prevention is necessary to lessen this incidence. For this, serious and long-term conservation intervention is required, so that the probability of human and leopard to encounter each other will be reduced.

\section{Acknowledgement}

I would like to thank Avishek Silwal, resident of Besishahar Rural Municipality Ward No-11, Lamjung, Nepal for being with me during the scat collection. IDEA WILD and The Rufford Small Grant for donating GPS and providing chemical cost in my previous research, which makes me easier to accomplish this work. Lastly, thank you my brother Samundra Kandel and my father Nabaraj Kandel for supporting and inspiring me.

\section{REFERENCES}

[1] Achyut A, Kreigenhofer B. Summer diet composition of the common leopard Panthera pardus (Carnivora: Felidae) in Nepal. Journal of Threatened Taxa. 2009 Nov 26:562-6.

[2] Ackerman BB, Lindzey FG, Hemker TP. Cougar food habits in southern Utah. The Journal of Wildlife Management. 1984 Jan 1:147-55.

[3] Athreya V, Odden M, Linnell JD, Krishnaswamy J, Karanth U. Big cats in our backyards: persistence of large carnivores in a human dominated landscape in India. PLoS One. 2013
Mar 6; 8(3):e57872.

[4] Athreya V, Odden M, Linnell JD, Krishnaswamy J, Karanth KU. A cat among the dogs: leopard Panthera pardus diet in a human-dominated landscape in western Maharashtra, India. Oryx. 2016 Jan; 50(1): 156-62.

[5] Jnawali, S., Baral, H., Lee, S., Acharya, K., Upadhyay, G., Pandey, M., Griffiths, J. (2011). The Status of Nepal Mammals: The National Red List Series, Department of National Parks and Wildlife Conservation Kathmandu, Nepal. Preface by Simon M. Stuart Chair IUCN Species Survival Commission.

[6] Meriggi A, Brangi A, Schenone L, Signorelli D, Milanesi P. Changes of wolf (Canis lupus) diet in Italy in relation to the increase of wild ungulate abundance. Ethology Ecology \& Evolution. 2011 Jul 1; 23(3): 195-210.

[7] Mukherjee, S., Goyal, S., \& Chellam, R. (1994). Standardisation of scat analysis techniques for leopard (Panthera pardus) in Gir National Park, Western India. Mammalia, 58(1), 139-144.

[8] Nowell K, Jackson P, editors. Wild cats: status survey and conservation action plan. Gland: IUCN; 1996.

[9] Ott T, Kerley GI, Boshoff AF. Preliminary observations on the diet of leopards (Panthera pardus) from a conservation area and adjacent rangelands in the Baviaanskloof region, South Africa. African Zoology. 2007 Apr 1; 42(1):31-7.

[10] Pienaar UD. Predator-prey relationships amongst the larger mammals of the Kruger National Park. Koedoe. 1969 May $25 ; 12(1): 108-76$.

[11] Rostro-García S, Kamler JF, Crouthers R, Sopheak K, Prum S, In V, Pin C, Caragiulo A, Macdonald DW. An adaptable but threatened big cat: density, diet and prey selection of the Indochinese leopard (Panthera pardus delacouri) in eastern Cambodia. Royal Society open science. 2018 Feb 7; 5(2): 171187.

[12] Thapa, TB. (2011). Habitat suitability evaluation for Leopard (Panthera pardus) using remote sensing and GIS in and around Chitwan National Park, Nepal. Saurashtra University.

[13] Thapa K, Shrestha R, Karki J, Thapa GJ, Subedi N, Pradhan NM, Dhakal M, Khanal P, Kelly MJ. Leopard Panthera pardus fusca density in the seasonally dry, subtropical forest in the Bhabhar of Terai Arc, Nepal. Advances in Ecology. 2014; 2014. 